\title{
Place of pitavastatin in the statin armamentarium: promising evidence for a role in diabetes mellitus
}

\author{
This article was published in the following Dove Press journal: \\ Drug Design, Development and Therapy \\ II May 20II \\ Number of times this article has been viewed
}

\author{
Yasuyuki Kawai \\ Ryoko Sato-Ishida \\ Atsushi Motoyama \\ Kouji Kajinami \\ Department of Cardiology, Kanazawa \\ Medical University, Uchinada, Japan
}

\begin{abstract}
Inhibitors of 3-hydroxy-3-methylglutaryl coenzyme A (HMG-CoA) reductase, known as statins, have revolutionized the treatment of hypercholesterolemia and coronary artery disease prevention. However, there are considerable issues regarding statin safety and further development of residual risk control, particularly for diabetic and metabolic syndrome patients. Pitavastatin is a potent statin with low-density lipoprotein (LDL) cholesterol-lowering effects comparable to those of atorvastatin or rosuvastatin. Pitavastatin has a high-density lipoprotein (HDL) cholesterol raising effect, may improve insulin resistance, and has little influence on glucose metabolism. Considering these factors along with its unique pharmacokinetic properties, which suggest minimal drug-drug interaction, pitavastatin could provide an alternative treatment choice, especially in patients with glucose intolerance or diabetes mellitus. Many clinical trials are now underway to test the clinical efficacy of pitavastatin in various settings and are expected to provide further information.
\end{abstract}

Keywords: HMG-CoA reductase inhibitor, pitavastatin, efficacy, safety, diabetes mellitus

\section{Introduction}

Statins can competitively inhibit 3-hydroxy-3-methylglutaryl coenzyme A (HMG$\mathrm{CoA}$ ) reductase, resulting in an effective decrease of low-density lipoprotein (LDL) cholesterol levels, and their use has been proved to reduce major cardiovascular events in both primary and secondary prevention. ${ }^{1}$ Since 1973 when Akira Endo discovered the first statin, ML236B (compactin or mevastatin) in Japan, a variety of statins have been developed all over the world. ${ }^{2}$ Pitavastatin (LIVALO ${ }^{\circledR}$ Tablet) is a synthetic statin developed by Nissan Chemical Industries Ltd (Tokyo, Japan), and Kowa Co Ltd (Nagoya, Japan). In Japan, the usual dose of pitavastatin is $1-2 \mathrm{mg} /$ day, and the maximum dose is $4 \mathrm{mg} /$ day. Pitavastatin appeared first on the Japanese market in September 2003, in Korea in July 2005, Thailand in January 2008, China in July 2009, and the US in June 2010. Pitavastatin will appear on the European market in 2011.

Recently, the prevalence of diabetes mellitus has greatly increased in Japan as well as in other industrialized countries, and prevention of coronary artery disease in diabetics has become an emerging issue to be resolved. One of the characteristics of patients with diabetes mellitus is impaired insulin secretion. Their beta cells cannot fully compensate for the insulin resistance caused by various environmental factors, and therefore they easily fall into chronic insulin insufficiency. In this article, we review clinical evidence for the use of pitavastatin in the treatment of hypercholesterolemia and in the prevention of atherosclerotic cardiovascular
Correspondence: Kouji Kajinami

Department of Cardiology, Kanazawa

Medical University, I-I Daigaku,

Uchinada 920-0293, Japan

Tel +8176286221 I

Fax +8I 762863780

Email kajinami@kanazawa-med.ac.jp 
diseases, especially focusing on efficacy in patients with diabetes mellitus, who are an important target population for statin treatment.

\section{Pharmacokinetic and pharmacodynamic properties}

\section{Pharmacokinetic properties}

Pitavastatin is distributed selectively to the target organ, the liver, and pharmacokinetic studies in rats conducted using ${ }^{14} \mathrm{C}$-pitavastatin have confirmed approximately 54 times greater radioactivity in the liver than in the serum ${ }^{3}$. Pitavastatin is a lipophilic statin. Its bioavailability is about $60 \%, \mathrm{t}_{\max }$ is $0.5-0.8$ hours, $\mathrm{t}_{1 / 2}$ is 11 hours, and the urinary excretion rate of both pitavastatin and its lactone form are less than $2 \%$. Pitavastatin shows enterohepatic circulation and is excreted with the feces. Pitavastatin is minimally metabolized by liver cytochrome P450 (CYP), which seems a favorable feature in terms of CYP-mediated drug-drug interaction. The CYP metabolic properties of pitavastatin are similar to those of pravastatin and rosuvastatin, and it is classified as a non-CYP metabolizable type (Table 1$){ }^{4}$

\section{Pharmacodynamic properties}

Pitavastatin has a characteristic structure consisting of a heptenoate basic structure with a quinoline ring, moieties of fluorophenyl and a cyclopropyl side chain (Figure 1), ${ }^{5}$ which provides optimal activity as a $\mathrm{HMG}-\mathrm{CoA}$ reductase inhibitor and better drug absorption. Figure 2 shows simulation imaging of the binding mode with the active site on the reductase. ${ }^{6}$ Pitavastatin inhibits $\mathrm{HMG-CoA}$ reductase and synthesis of cholesterol in the liver like other statins, however, the $\mathrm{IC}_{50}$ for the inhibition of cholesterol synthesis from $\left[{ }^{14} \mathrm{C}\right]$ acetic acid in the cultured human hepatoma cell line HepG2 was found to be $5.8 \mathrm{nM}$, being 2.9-fold higher than that of simvastatin and 5.7-fold higher than that of atorvastatin. ${ }^{7}$ The $\mathrm{ED}_{50}$ of oral pitavastatin for inhibition of sterol synthesis in the rat liver was $0.13 \mathrm{mg} / \mathrm{kg}$, being 2.8 -fold and 18-fold higher, respectively, than that of simvastatin and that of pravastatin. ${ }^{8}$

\section{Clinical studies of pitavastatin Efficacy \\ Improvement of dyslipidemia \\ Effects on LDL cholesterol}

In the Steno-2 Study, intensive, multifactorial care of patients with type 2 diabetes led to reduction of rates of death and cardiovascular disorders..$^{9,10}$ By contrast, in the ACCORD trial, intensive glucose lowering in type 2 diabetics increased mortality and did not significantly reduce major cardiovascular events. ${ }^{11}$ In the ADVANCE trial, intensive glucose

Table I Pharmacokinetic parameters of statins

\begin{tabular}{|c|c|c|c|c|c|c|c|}
\hline Statin & Pitavastatin & Atorvastatin & Fluvastatin & Lovastatin & Pravastatin & Rosuvastatin & Simvastatin \\
\hline Molecular weight & 881 & 1209 & 433.5 & 405 & 446.5 & 1001 & 418.15 \\
\hline Origin & Synthetic & Synthetic & Synthetic & Microbial & $\begin{array}{l}\text { Semi-synthetic } \\
\text { (microbial origin) }\end{array}$ & Synthetic & $\begin{array}{l}\text { Semi-synthetic } \\
\text { (microbial origin) }\end{array}$ \\
\hline Racemic & No & No & Yes & No & No & No & No \\
\hline Prodrug & No & No & No & Yes & No & No & Yes \\
\hline $\log P$ & 1.49 & I.II & 1.27 & 1.70 & -0.84 & -0.33 & 1.60 \\
\hline Absorption (\%) & 80 & 30 & 98 & 31 & 37 & 50 & $65-85$ \\
\hline Hepatic excretion (\%) & NA & $>70$ & 68 & $>70$ & 66 & 90 & $78-87$ \\
\hline Bioavailability (\%) & $>60$ & 12 & $10-35$ & $<5$ & 17 & 20 & $<5$ \\
\hline $\begin{array}{l}\text { Effect of food on } \\
\text { bioavailability (\%) }\end{array}$ & No & Yes $(\downarrow$ I3) & Yes $(\downarrow 15-25)$ & Yes $(\uparrow 50)$ & Yes $(\downarrow 30)$ & No & No \\
\hline Protein binding (\%) & 96 & $>98$ & $>98$ & $96-98.5$ & $43-54$ & 88 & $>95$ \\
\hline $\mathrm{T}_{\max }$ & $0.5-0.8$ & $2.0-4.0$ & $0.5-1.5$ & 2.8 & $0.9-1.6$ & 3 & I.3-2.4 \\
\hline $\mathrm{T}_{1 / 2}$ & II & $11-30$ & $0.5-2.3$ & $2.5-3.0$ & $0.8-3.0$ & 20 & $1.9-3.0$ \\
\hline Renal excretion & $<2$ & 2 & 6 & 30 & 60 & 10 & 13 \\
\hline $\begin{array}{l}50 \% \text { inhibitory } \\
\text { concentration (nmol/L) }\end{array}$ & 6.8 & 15.2 & 17.9 & $2.7-I I . I$ & 55.1 & 12 & I8. I \\
\hline $\begin{array}{l}\text { Lipid-lowering } \\
\text { Metabolites }\end{array}$ & No & Yes, active & $\begin{array}{l}\text { Yes, mainly } \\
\text { inactive }\end{array}$ & Yes & $\begin{array}{l}\text { Yes, mainly } \\
\text { active }\end{array}$ & No & Yes \\
\hline Range of dose (mg) & $\mathrm{I}-4$ & $10-80$ & $20-80$ & $10-80$ & $5-40$ & $5-80$ & $5-80$ \\
\hline $\begin{array}{l}\text { CYP isoforms } \\
\text { primarily involved } \\
\text { with metabolic pathway }\end{array}$ & $\begin{array}{l}\text { CYP2C9 } \\
\text { Minimally }\end{array}$ & CYP3A4 & CYP2C9 & CYP3A4 & $\begin{array}{l}\text { CYP3A4 } \\
\text { Minimally }\end{array}$ & $\begin{array}{l}\text { CYP2C9 } \\
\text { Minimally }\end{array}$ & CYP3A4 \\
\hline
\end{tabular}

Note: Log $P$, logarithm of base 10 of the n-octanol/water partition coefficient of active hydroxy forms of statins. Adapted from Saito Y. ${ }^{4}$ 


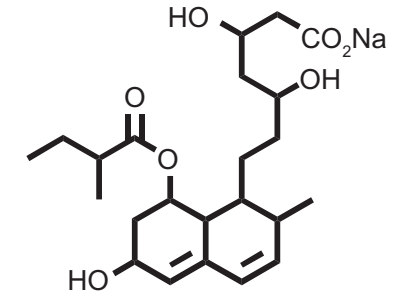

Pravastatin

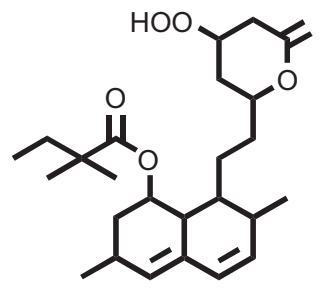

Simvastatin

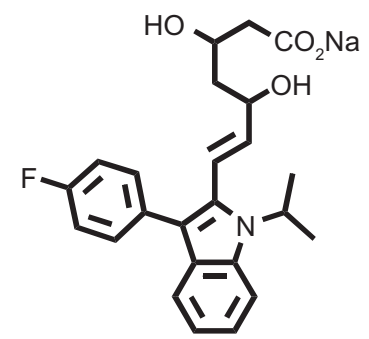

Fluvastatin

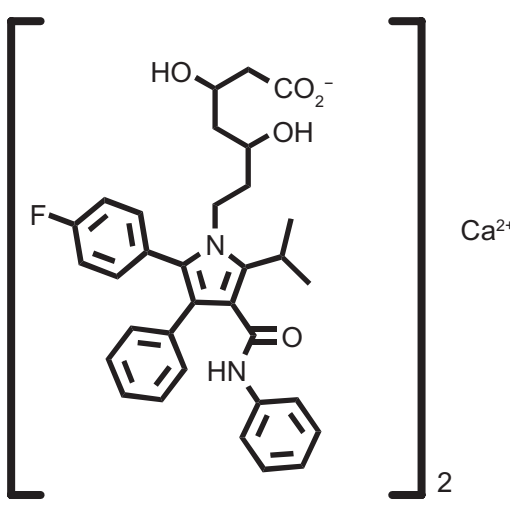

Atorvastatin

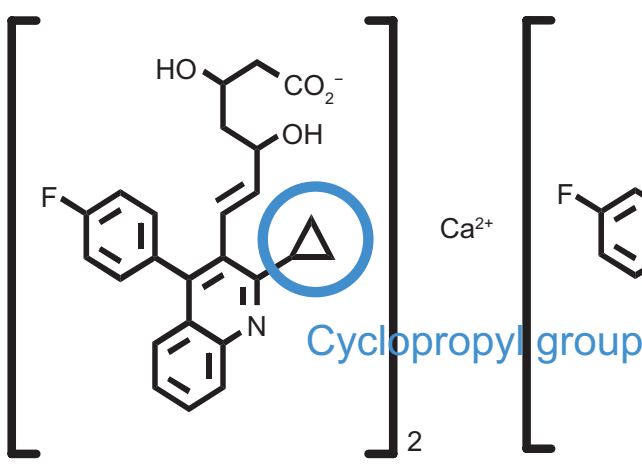

Pitavastatin

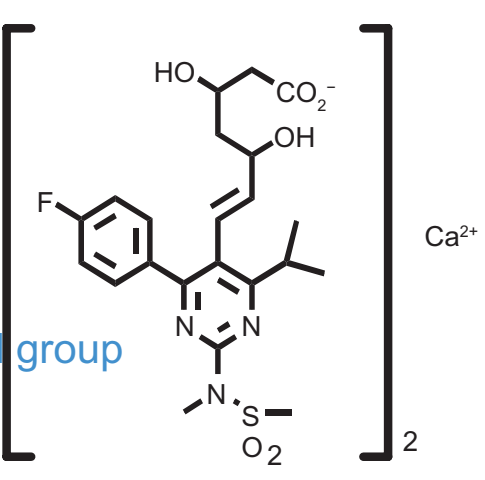

Rosuvastatin

Figure I Chemical structures of statins. The circled moiety on pitavastatin denotes the unique cyclopropyl group. Adapted from Catapano. ${ }^{5}$

lowering in type 2 diabetic subjects significantly reduced the composite outcome of major macrovascular or microvascular events, but there was no significant reduction in major macrovascular events. ${ }^{12}$

Contrary to this controversy over the effects of intensive glucose lowering on cardiovascular events, the importance of the management of LDL cholesterol in diabetes mellitus has already been shown by many. In the United Kingdom prospective diabetes study (UKPDS 23) ${ }^{13}$ and the Japan Diabetes Complications Study (JDCS 9th),${ }^{14}$ LDL cholesterol was the top-ranked risk factor for coronary artery disease

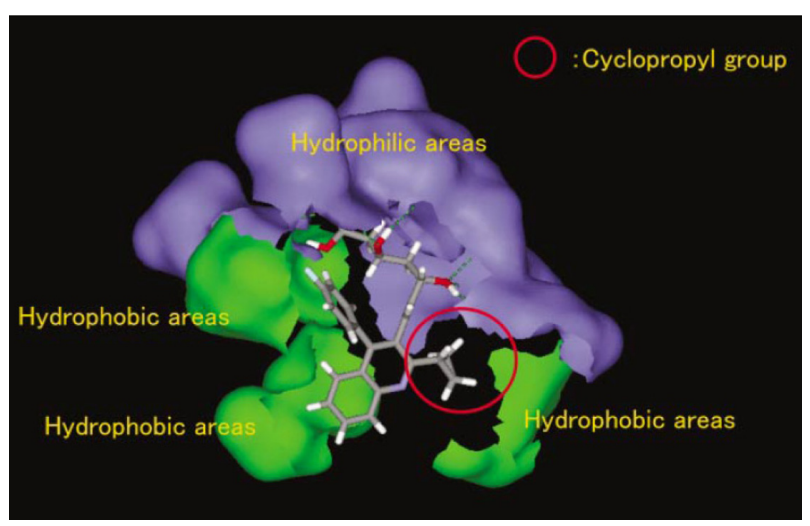

Figure 2 Pitavastatin in the complex with active site of human HMG-CoA reductase. Adapted from Yamazaki et al. ${ }^{6}$ in type 2 diabetes. The Cholesterol Treatment Trialists' (CTT) collaborators reported the importance of LDL cholesterol lowering therapy with statins in 18,686 people with diabetes. ${ }^{15}$ Based on these findings, in the Japan Atherosclerosis Society (JAS) Guideline, diabetic patients are classified as Category III (high-risk group) and their LDL cholesterol treatment goal is less than $120 \mathrm{mg} / \mathrm{dL}$, or less than $100 \mathrm{mg} / \mathrm{dL}$ if they have coronary artery disease. ${ }^{16}$ In the United States, the consensus conference report from the ADA/ACC recommended that the LDL cholesterol goal of the highest-risk patients, with established diabetes with one or more additional major cardiovascular disease risk factor, should be less than $70 \mathrm{mg} / \mathrm{dL} .{ }^{17}$ In the prevention of coronary artery diseases in diabetic patients, it may be important to pay attention not only to glycemic control but also to lipid profile.

To achieve these LDL cholesterol goals, intensive medication in which statins play a pivotal role is required. Six statins are currently available in the Japanese market and pitavastatin is one of the three potent statins. In the Japanese dose-response trial, the LDL cholesterol lowering effect of pitavastatin after 12 weeks was $34 \%(n=81)$ at a dose of $1 \mathrm{mg}, 42 \%(\mathrm{n}=75)$ at a dose of $2 \mathrm{mg}$, and $47 \%(\mathrm{n}=76)$ at a dose of $4 \mathrm{mg} .{ }^{18}$ In the LIVES Study, a large-scale, prospective post-marketing surveillance of pitavastatin $^{19}$ and the JAPAN-ACS study, a prospective, randomized, open-label, 
parallel group study with blind endpoint evaluation at 33 centers in Japan, ${ }^{20}$ the LDL cholesterol lowering effect among diabetic patients was almost the same as that in nondiabetic subjects. Nomura et al reported that 6 months administration of pitavastatin at $2 \mathrm{mg} /$ day significantly reduced LDL cholesterol, from 155 to $88 \mathrm{mg} / \mathrm{dL}$, in 45 diabetic patients (Figure 3). ${ }^{21}$ In the CHIBA Study, a randomized, multicentered, open-label study comparing the efficacy and safety of pitavastatin with that of atorvastatin in Japanese patients with hypercholesterolemia, 12 weeks administration of pitavastatin $2 \mathrm{mg} /$ day $(\mathrm{n}=126)$ significantly reduced LDL cholesterol by $42.6 \%$, which was almost the same reduction produced by atorvastatin $10 \mathrm{mg} /$ day $(\mathrm{n}=125){ }^{22}$

In Europe, a randomized, double-blind, 12-week study to compare pitavastatin and simvastatin reported that the administration of pitavastatin $2 \mathrm{mg}$ /day reduced LDL cholesterol by $39.0 \%(n=307)$, which was significantly greater than that achieved with simvastatin $20 \mathrm{mg} /$ day $(35.0 \%, \mathrm{n}=107)$, and that the administration of pitavastatin $4 \mathrm{mg} /$ day reduced LDL cholesterol by $44.0 \%(\mathrm{n}=319)$, which was comparable to that of simvastatin $40 \mathrm{mg} /$ day $(42.8 \%, \mathrm{n}=110) .{ }^{23}$ Another European randomized, double-blind, comparative study reported that 12 -week administration of pitavastatin $2 \mathrm{mg} /$ day reduced LDL cholesterol by $37.9 \%(\mathrm{n}=315)$, which was comparable to that of atorvastatin $10 \mathrm{mg} /$ day $(37.8 \%, \mathrm{n}=102)$, and that the administration of pitavastatin $4 \mathrm{mg} /$ day reduced LDL cholesterol by $44.6 \%(\mathrm{n}=298)$ which was comparable to that of atorvastatin $20 \mathrm{mg} /$ day $(43.5 \%$, $\mathrm{n}=102) .^{24}$

High-density lipoprotein (HDL) cholesterol

Insulin resistance causes various dyslipidemic states such as increase of small dense LDL particles, remnant lipoprotein,

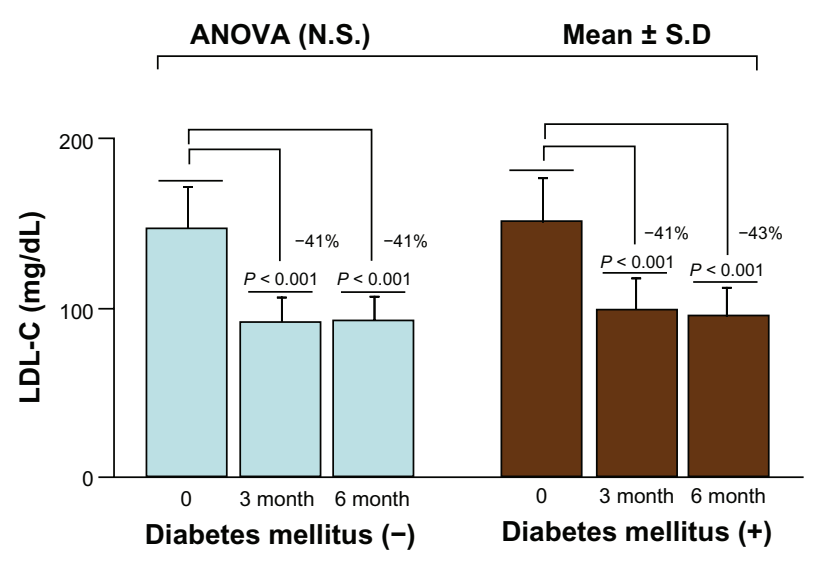

Figure 3 Changes in LDL cholesterol before and after administration of pitavastatin $2 \mathrm{mg} /$ day in hyperlipidemic patients with and without type 2 diabetes mellitus. Adapted from Nomura et al. ${ }^{21}$ and decrease of HDL cholesterol. In diabetes mellitus, reduced activity of lipoprotein lipase (LPL) leads to low HDL cholesterol because of impaired catabolism of VLDL. ${ }^{25}$ In addition, it has recently been reported that low HDL cholesterol in type 2 diabetic patients is associated with hypoadiponectinemia. ${ }^{26}$ In diabetes mellitus, the management of low HDL cholesterol is important. In the subanalysis of the J-LIT study, an increase of $10 \mathrm{mg} / \mathrm{dL}$ in HDL cholesterol was associated with a $34.9 \%$ decrease in the risk of coronary events in type 2 diabetes. $^{27}$

One of the most striking characteristics of pitavastatin is the HDL cholesterol increase which continues for about 2 years from the start of administration. Pitavastatin $1-4 \mathrm{mg} /$ day significantly increased the serum HDL cholesterol levels in a long-term (52 weeks) administration study. ${ }^{28}$ In the LIVES Study, 2-year treatment with pitavastatin 1-4 mg/day significantly increased serum HDL cholesterol levels from 58.8 to $60.8 \mathrm{mg} / \mathrm{dL}(+5.9 \%)$ in all subjects $(\mathrm{n}=3427)$ and from 35.1 to $43.3 \mathrm{mg} / \mathrm{dL}(+24.6 \%)$ in low HDL cholesterol $(<40 \mathrm{mg} / \mathrm{dL})$ subjects $(\mathrm{n}=346)$ (Figure 4$).{ }^{29}$ In the PIAT Study to compare pitavastatin $2 \mathrm{mg} /$ day $(\mathrm{n}=88)$ and atorvastatin $10 \mathrm{mg} /$ day $(\mathrm{n}=85)$, pitavastatin gave greater increases in HDL cholesterol and ApoA-1 levels than atorvastatin after 1 year of treatment. ${ }^{30}$ In the European 1 -year trial $(n=1346)$, pitavastatin $4 \mathrm{mg} /$ day increased HDL cholesterol from 50.5 to $57.0 \mathrm{mg} / \mathrm{dL}(+14.3 \%) .{ }^{31}$

The mechanisms of the increase of HDL cholesterol caused by pitavastatin have been reported by several investigators. In hepatocytes, pitavastatin increases ApoA-1 gene expression through the activation of peroxisome proliferator-activated receptor (PPAR)- $\alpha,{ }^{32}$ which is considered a major regulator of intra- and extracellular fatty acid metabolism, and also increases ApoA-1 secretion by elevating ATP binding cassette A1 (ABCA1) expression via activation of LXR $\alpha .{ }^{33}$ Although pitavastatin decreases circulating cholesterylester transfer protein (CETP) mass in hypercholesterolemic patients, ${ }^{34}$ induction of ApoA-1 production may play a central role in increasing HDL cholesterol. ${ }^{30,35}$

\section{Non-HDL cholesterol}

Non-HDL cholesterol is easily calculated as: total cholesterol minus HDL cholesterol. The measurement of non-HDL cholesterol is reliable even in the nonfasting sample and is noted as the secondary target after the achievement of LDL cholesterol goals. The goal for non-HDL cholesterol has been reported to be the level of LDL cholesterol plus $30 \mathrm{mg} / \mathrm{dL} .^{36}$ In type 2 diabetics, several characteristics such as elevated triglycerides, decreased HDL cholesterol, and elevated small 

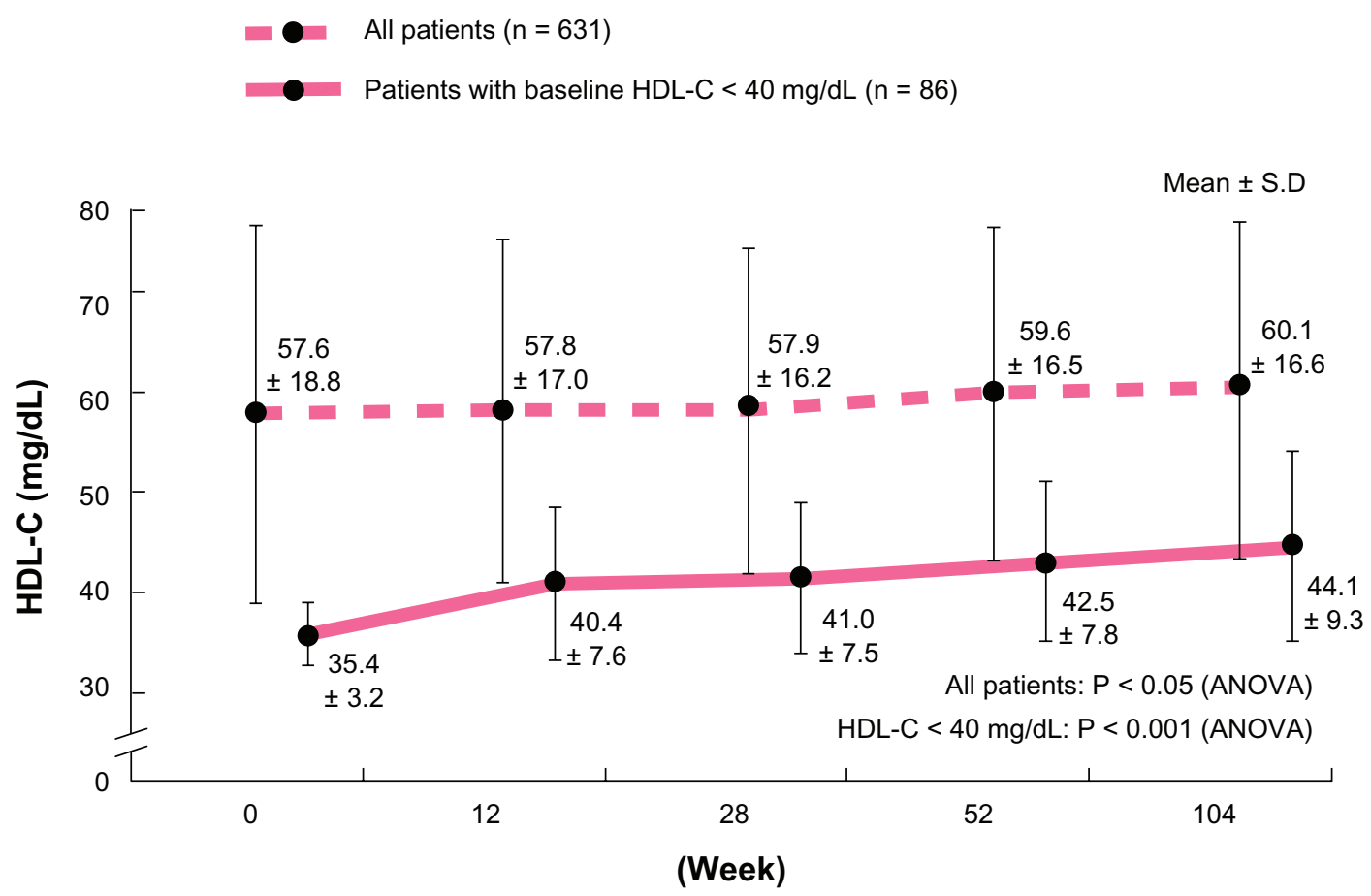

Figure 4 The time course of HDL cholesterol for 104 weeks before and after administration of pitavastatin I-4 mg/day in the LIVES study. Adapted from Teramoto et al..$^{29}$

dense LDL, are well-known. ${ }^{25}$ Because non-HDL cholesterol reflects all apolipoprotein B-containing atherogenic lipoproteins, non-HDL cholesterol may be useful in predicting cardiovascular disease in patients with type 2 diabetes mellitus. In the Strong Heart Study, non-HDL cholesterol was a strong predictor of coronary heart disease in men and women with diabetes. ${ }^{37}$

In the CHIBA Study, the reduction of non-HDL cholesterol by pitavastatin $2 \mathrm{mg} /$ day $(39.0 \%)$ was similar to that achieved with atorvastatin $10 \mathrm{mg}$ /day (40.3\%). However, in the atorvastatin group, the waist circumference, body weight and BMI were significantly correlated with percent reduction of non-HDL cholesterol, whereas pitavastatin showed consistent reduction of non-HDL cholesterol irrespective of these variables. ${ }^{22}$

\section{Remnant lipoprotein, small dense LDL}

Serum levels of remnant-like particle (RLP) cholesterol and small dense LDL are elevated in diabetic patients as a result of insulin resistance. ${ }^{38,39}$ RLP and small dense LDL are more susceptible to oxidation and in turn more atherogenic relative to LDL particles. Effects of pitavastatin on these specific lipoprotein particles are as follows.

In 28 diabetic patients, all of whom were treated with pitavastatin $2 \mathrm{mg} /$ day for 8 weeks, LDL cholesterol significantly decreased by $36.1 \%$ (from 168.4 to $105.4 \mathrm{mg} / \mathrm{dL}$ ), small dense LDL significantly decreased by $10.3 \%$ (from 29.9 to $19.7 \%$ ), peak particle diameter of LDL significantly increased by $0.7 \mathrm{~nm}$ (from 26.363 to $27.095 \mathrm{~nm}$ ), and RLP cholesterol significantly decreased by $2.49 \mathrm{mg} / \mathrm{dL}$ (from 6.62 to $4.13 \mathrm{mg} / \mathrm{dL}) .{ }^{40}$ In another report, administration of pitavastatin $1 \mathrm{mg} /$ day for 3 months significantly reduced small dense LDL from 37 to $25 \mathrm{mg} / \mathrm{dL}$ measured in type 2 diabetic patients. ${ }^{41}$

\section{Vascular effect}

In diabetics, vascular endothelial function can be impaired by hyperglycemia or oxidized lipoproteins. ${ }^{42,43}$

In Watanabe heritable hyperlipidemic myocardial infarction-prone rabbits (WHHL-MI rabbits), 8 week treatment with $0.5 \mathrm{mg} / \mathrm{kg} /$ day pitavastatin resulted in a significant increase in acetylcholine induced nitric oxide (NO) production. ${ }^{44}$ The silent mating type information regulation 2 homolog 1 (SIRT1) gene has been recognized as a key regulator of vascular endothelial homeostasis, controlling angiogenesis, endothelial senescence, and dysfunction. Administration of pitavastatin increased endothelial nitric oxide synthase (eNOS), SIRT1, and catalase expression and decreased endothelial senescence in streptozotocindiabetic mice. ${ }^{45}$ In clinical settings, pitavastatin $2 \mathrm{mg}$ /day $(\mathrm{n}=37)$ increased flow-mediated dilatation (FMD) more in comparison with atorvastatin $10 \mathrm{mg} /$ day $(\mathrm{n}=34)$ after 
2 weeks treatment (relative change $82 \%$ vs $40 \%, P<0.05$ ). ${ }^{46}$ In type 2 diabetic patients, administration of pitavastatin $2 \mathrm{mg} /$ day for 12 months $(\mathrm{n}=45)$ significantly decreased vascular stiffness as assessed by cardio-ankle vascular index (CAVI), which was associated significantly with a decrease in malondialdehyde-LDL (MDA-LDL). ${ }^{47}$ These results suggest that pitavastatin may produce beneficial effects on vasculature.

\section{Coronary artery}

From the VH-IVUS analysis, coronary plaques in diabetic patients showed increased necrotic core and dense calcium, and VHD-TCFA (VH IVUS-derived thin-cap fibroatheroma) and VHD-FCA (VH IVUS-derived fibrocalcific atheroma) were more frequently observed in diabetic patients than in nondiabetic patients. ${ }^{48}$ In another pooled analysis, coronary plaque build-up was more progressive in diabetic patients than in nondiabetic patients. ${ }^{49}$

The JAPAN-ACS study was a randomized prospective study with blind endpoint evaluation in Japanese acute coronary syndrome (ACS) patients, to evaluate the effect of pitavastatin $4 \mathrm{mg} /$ day $(\mathrm{n}=125)$ or atorvastatin $20 \mathrm{mg} /$ day $(n=127)$ on coronary artery plaques as assessed by intravascular ultrasound. ${ }^{50}$ After 8-12 months treatment, the coronary plaque volume significantly decreased by $16.9 \%$ in the pitavastatin group and $18.1 \%$ in the atorvastatin group, suggesting pitavastatin was comparable to atorvastatin (Figure 5). In a subanalysis of the JAPAN-ACS study to compare diabetic patients with nondiabetic patients, changes in coronary plaque volume were significantly associated with the reduction of LDL cholesterol in diabetic patients, whereas this relationship was not observed in nondiabetic patients. ${ }^{20}$ In another subanalysis of JAPAN-ACS study, diabetic ACS patients showed greater coronary plaque regression than total ACS patients after intensive LDL cholesterol lowering therapy. ${ }^{51}$ In another study to compare pitavastatin $2 \mathrm{mg} /$ day $(\mathrm{n}=80)$ with atorvastatin $10 \mathrm{mg} /$ day $(\mathrm{n}=80)$ in ACS patients, only pitavastatin $2 \mathrm{mg}$ /day produced significant regression of coronary artery plaque volume in 2-3 weeks. ${ }^{52}$

In the prevention of coronary artery diseases, plaque stabilization is another therapeutic target in addition to plaque regression. Yellow color in coronary atheromas as assessed by angioscopy was reported to be an indicator of plaque rupture risk, and diabetic patients were reportedly more likely to have higher yellow color grades than nondiabetics. ${ }^{53}$ In the TOGETHAR trial which evaluated the effects of pitavastatin on coronary plaque stabilization using angioscopy and IVUS, pitavastatin $2 \mathrm{mg} /$ day $(\mathrm{n}=46)$ significantly reduced the yellow grade from 2.9 to 2.6 after 52 weeks' treatment. ${ }^{54}$

\section{Carotid artery}

Effects of pitavastatin on carotid plaques were assessed by measuring plaque echolucency using carotid ultrasound with integrated backscatter (IBS) analysis. ${ }^{55}$ In patients with ACS, pitavastatin $4 \mathrm{mg} /$ day $(\mathrm{n}=33$ ) significantly improved the carotid plaque echolucency within 1 month of therapy;

\section{Change in LDL-cholesterol}

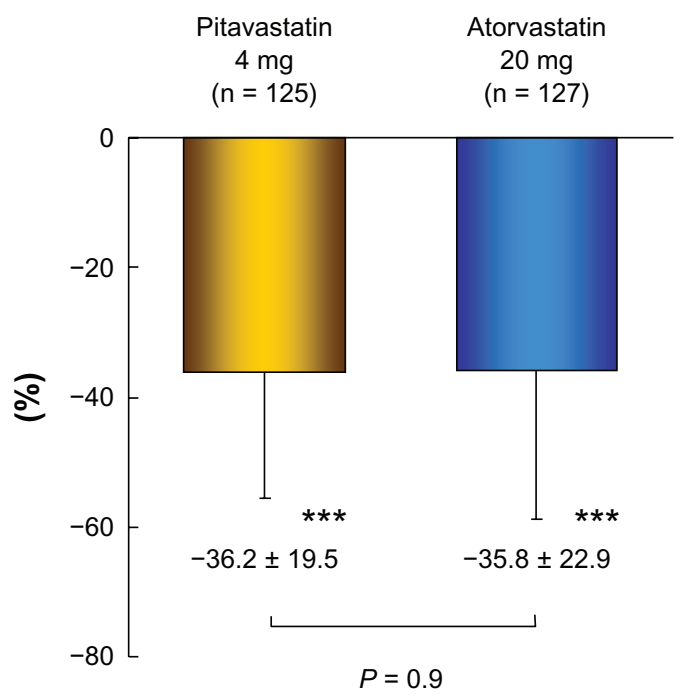

\section{Change in plaque volume}

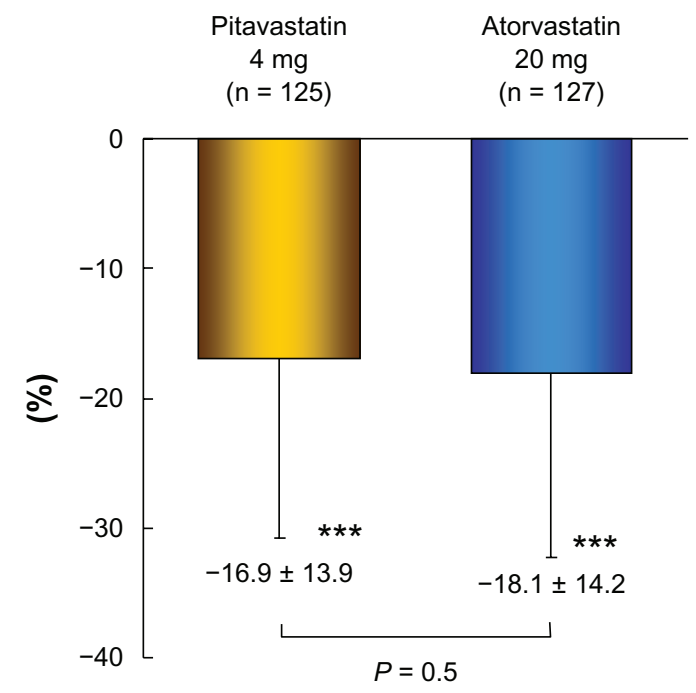

Figure 5 Changes in LDL cholesterol and plaque volume for 12 months in the JAPAN-ACS study. Adapted from Hiro et al. ${ }^{50}$

**** $P<0.001$ mean \pm S.D. 
pitavastatin improved the calibrated IBS value from -18.7 to $-12.7 \mathrm{~dB}$, which was almost the same value obtained in patients with stable coronary artery disease: $-13.2 \mathrm{~dB}$ $(n=32)$. Echolucent carotid plaques with low IBS value were reported to be associated with future coronary events in patients with coronary artery disease ${ }^{56}$ and pitavastatin may be useful in preventing coronary events by stabilizing plaques. In addition to plaque characteristics, two ongoing trials, PEACE (UMIN 000001229, NCT 00711919) and NTPP (UMIN C000000328), will clarify the effect of pitavastatin on carotid intima-media thickness, and another ongoing trial, EPOCH-CAS (UMIN 000004113), will examine the effect of pitavastatin on perioperative ischemic complications after carotid artery stenting.

\section{Kidney}

Accumulating evidence suggests that renal dysfunction promotes the development of cardiovascular diseases. For example, from a recent meta-analysis, low estimated glomerular filtration rate (eGFR) of less than $60 \mathrm{~mL} / \mathrm{min} / 1.73 \mathrm{~m}^{2}$, and high urine albumin-to-creatinine ratio (ACR) of $10 \mathrm{mg} / \mathrm{g}$ or more were independent predictors of all-cause mortality and cardiovascular mortality in the general population. ${ }^{57}$ These findings have stimulated interest in the potential effects of statin treatment on kidney function, or other surrogate markers related to tubuloglomerular damage.

In the LIVES Study subanalysis, pitavastatin $1-4 \mathrm{mg} /$ day significantly increased eGFR from 47.8 to $53.2 \mathrm{~mL} / \mathrm{min} / 1.73 \mathrm{~m}^{2}$ over 104 weeks in patients with a baseline eGFR less than $60 \mathrm{~mL} / \mathrm{min} / 1.73 \mathrm{~m}^{2}(\mathrm{n}=958)$ (Figure 6). Using multivariate analysis in the LIVES Study, proteinuria and HDL cholesterol were negatively and positively associated with increased eGFR, respectively. ${ }^{58}$ In the GREACE study, various statin

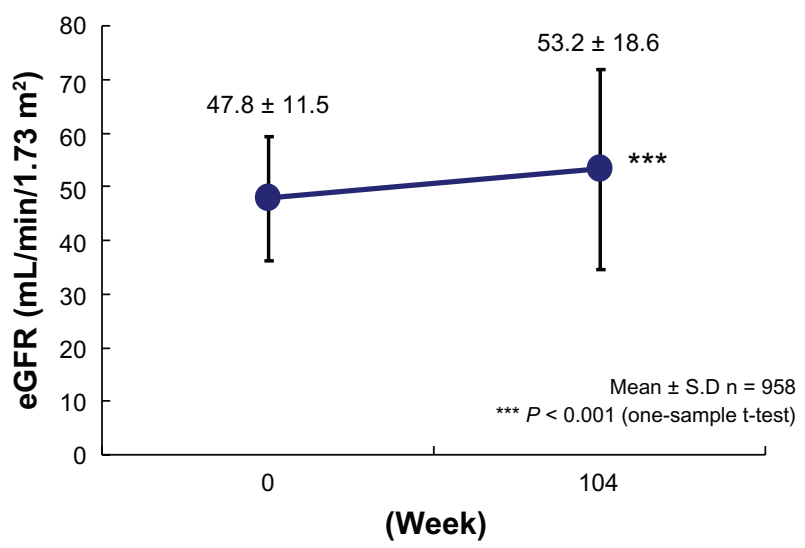

Figure 6 Changes in eGFR before and after administration of pitavastatin I-4 mg/day in the LIVES study. Baseline eGFR $<60 \mathrm{~mL} / \mathrm{min} / \mathrm{l} .73 \mathrm{~m}^{2}$.

Adapted from Kimura et al. ${ }^{58}$ treatments (mainly atorvastatin) over 3 years significantly increased eGFR by $9.8 \%(P<0.0001, \mathrm{n}=880)$. Multiple regression analysis showed that every $5 \%$ statin-induced HDL cholesterol increase significantly and independently contributed to eGFR improvement. ${ }^{59}$ Furthermore, in patients with early diabetic nephropathy, pitavastatin $1 \mathrm{mg} /$ day $(\mathrm{n}=10)$ significantly reduced urinary albumin excretion and urinary liver-type fatty acid-binding protein (L-FABP), which reflected the extent of tubulointerstitial damage. ${ }^{60}$

The precise mechanism underlying renal protection by statins remains unknown. Moorhead et al proposed that chronic progressive kidney disease may be mediated by abnormalities of lipid metabolism. ${ }^{61,62}$ Several other reports have proposed potential explanations. Firstly, as observed in the LIVES Study, HDL cholesterol showed a positive association with increasing eGFR, ${ }^{58}$ which suggests the possibility that the antioxidant properties of HDL cholesterol may play a role in eGFR increase. Paraoxonase 1 (PON1) is known to be located on HDL particles and to inhibit the oxidation of LDL and HDL. ${ }^{63}$ Pitavastatin activates transcription of the PON1 gene, ${ }^{64}$ and this may lead to antioxidization which improves endothelial function, and thus renal function. In Imai rats, used as a model of focal segmental glomerulosclerosis (FSGS), pitavastatin prevented renal injuries, and lag times for LDL and HDL oxidation were prolonged by the treatment of pitavastatin. ${ }^{65}$ Secondly, pitavastatin suppresses glomerular mesangial cell proliferation by blocking Ras processing and MAP kinase activation. ${ }^{66}$ Thirdly, pitavastatin is reported to cause upregulation of the $\mathrm{SLCO} 4 \mathrm{C} 1$ transporter, which eliminates uremic toxins. This could provide a novel therapeutic potential for statins in chronic kidney disease (CKD) patients, if future studies support this idea. ${ }^{67}$

\section{Cardiovascular event}

In the JAPAN-ACS study, major adverse cardiac events (MACE) were evaluated prospectively. ${ }^{50}$ There was no significant difference in MACE; $20.4 \%$ in pitavastatin $4 \mathrm{mg} /$ day group and $22.8 \%$ in atorvastatin $20 \mathrm{mg}$ /day group. In the JAPAN-ACS subanalysis of patients with diabetes mellitus, the rate of MACE was $29.9 \%$ in diabetic patients, which was significantly greater than that in nondiabetic patients $(18.2 \%) .{ }^{20}$

\section{Anti-inflammatory effect and antioxidant effect}

C-reactive protein (CRP) is an important risk marker for atherosclerotic cardiovascular disease. In the PROVE ITTIMI22 Study, ACS patients who have low CRP levels after statin therapy have better clinical outcomes than those 
with higher CRP levels, regardless of the resultant level of LDL cholesterol. ${ }^{68}$ In the Hisayama Study, in which a total of 2,589 Japanese participants aged 40 years or older were followed up for 14 years, the risk of coronary heart disease in the highest quartile group of high-sensitivity CRP (hsCRP) levels was 2.98-fold higher than that in the lowest group even after controlling for other cardiovascular risk factors. ${ }^{69}$ In the JUPITER Trial, rosuvastatin significantly reduced the incidence of major cardiovascular events in healthy persons with elevated hsCRP. ${ }^{70}$ Moreover, in some studies, elevated hsCRP was reported to be a predictor of the development of diabetes. ${ }^{71,72}$ Anti-inflammatory effects may be important in preventing not only cardiovascular disease but also the onset of diabetes.

In the KISHIMEN Trial, administration of pitavastatin 1-2 $\mathrm{mg}$ /day for 12 months significantly decreased hsCRP by $34.8 \%$ (from 0.69 to $0.45 \mathrm{mg} / \mathrm{L}$ ) in Japanese subjects with hypercholesterolemia $(\mathrm{n}=31) .{ }^{73}$ In another small trial, administration of pitavastatin $4 \mathrm{mg}$ /day for 1 month significantly decreased hsCRP from 0.64 to $0.28 \mathrm{mg} / \mathrm{dL}$ in Japanese ACS patients $(\mathrm{n}=33){ }^{55}$

Anti-oxidant effect is another important factor in preventing cardiovascular disease and diabetes mellitus. Oxidized LDL plays a key role in the initiation and development of atherosclerosis. ${ }^{74-76}$ In Japanese type 2 diabetic patients, an inverse correlation between 8-hydroxydeoxyguanosine (8-OHdG) positive islet beta-cells and beta-cell volume density was observed. ${ }^{77}$ Pitavastatin $2 \mathrm{mg}$ /day for 12 months $(n=45)$ significantly decreased urinary $8-O H d G$ excretion from 11.3 to $8.4 \mathrm{ng} / \mathrm{mg} \mathrm{Cr}(P<0.05)$ and serum MDA-LDL levels from 170 to $114 \mathrm{U} / \mathrm{L}(P<0.01)$ in type 2 diabetic patients. ${ }^{47}$ Also pitavastatin $2 \mathrm{mg} /$ day for 6 months $(\mathrm{n}=25)$ significantly decreased circulating ligand for lectin-like oxidized LDL receptor-1 (LOX-1), a receptor for oxidized LDL expressing in vascular endothelial cells, from 867 to $435 \mathrm{ng} / \mathrm{mL}(P<0.0001){ }^{78}$

\section{Improving insulin resistance}

In the WOSCOPS subanalysis, pravastatin reduced the onset of diabetes by $30 \%$, suggesting its beneficial influence on glucose tolerance. ${ }^{79}$ Some reports suggested that pitavastatin improved insulin resistance. Pitavastatin increased glucose uptake in $\mathrm{KKA}^{\mathrm{y}}$ mice, ${ }^{80}$ and the response to intraperitoneal insulin was greater in the pitavastatin-treated mice than in the untreated $\mathrm{KKA}^{\mathrm{y}}$ mice. ${ }^{81}$ Also, pitavastatin improved HOMA-R in type 2 diabetic patients $(n=31)$ after 6 month treatment. ${ }^{82}$ A recent study suggested that HDL particle improved glucose metabolism in patients with type
2 diabetes. ${ }^{83}$ Thirteen patients with type 2 diabetes were treated for 4 hours with intravenous reconstituted HDL (rHDL) and placebo in a double-blind, placebo-controlled crossover study. Plasma glucose and plasma insulin were reduced and increased more, respectively, during the rHDL period than during the placebo period. Also, both HDL and ApoA-1 increased glucose uptake in primary human skeletal muscle cell cultures established from patients with type 2 diabetic patients. These findings suggest that HDL may be associated with improving insulin resistance. The potential of pitavastatin to increase HDL cholesterol and ApoA-1 in a long-term treatment may be useful not only in preventing cardiovascular disease but also in improving insulin resistance. From this viewpoint, the Japan Prevention Trial of Diabetes by Pitavastatin in Patients with Impaired Glucose Tolerance (J-PREDICT) study $(\mathrm{n}=1240)$, which examines the preventative effects of pitavastatin plus lifestyle modification on the development of new-onset diabetes in Japanese patients with impaired glucose tolerance (IGT), is now underway.

\section{Safety}

\section{Effects on glucose metabolism}

Effects of statins on glucose metabolism are an issue currently under debate. ${ }^{84,85}$ For example, in the JUPITER trial, rosuvastatin significantly prevented vascular events in men and women with elevated hsCRP, but increased the incidence of new-onset diabetes more than the placebo. ${ }^{70}$ A meta-analysis showed that statin therapy was associated with a significantly increased risk $(9 \%)$ of the development of diabetes, and meta-regression analysis showed that the risk of development of diabetes with statins was highest in trials with older participants irrespective of baseline bodymass index or magnitude of LDL cholesterol reduction. ${ }^{86}$ However, this study also suggested that the increment of risk remained small both in absolute value and in comparison with coronary event reduction, and that clinical practice in patients with moderate or high cardiovascular risk or existing cardiovascular disease should not be changed.

The advantage of pitavastatin for dyslipidemia in diabetic patients is that pitavastatin hardly influences glycemic control. In the CHIBA Study subanalysis of diabetic patients, atorvastatin $10 \mathrm{mg} /$ day $(\mathrm{n}=22)$ significantly increased glycoalbumin, but pitavastatin $2 \mathrm{mg} /$ day $(\mathrm{n}=23)$ had no significant influence on fasting plasma glucose, HbA1c, insulin, glycoalbumin, or HOMA-R. ${ }^{87}$ In another retrospective analysis to compare the effects of atorvastatin $10 \mathrm{mg} /$ day $(\mathrm{n}=74)$, pravastatin $10 \mathrm{mg} /$ day $(\mathrm{n}=70)$, and pitavastatin $2 \mathrm{mg} /$ day $(\mathrm{n}=76)$ on glycemic control during a 3-month 
treatment period, only atorvastatin significantly increased plasma glucose (from 147 to $176 \mathrm{mg} / \mathrm{dL}$ ) and $\mathrm{HbA} 1 \mathrm{c}$ (from 7.0 to $7.4 \%$ ). Neither pravastatin nor pitavastatin had any significant influence on plasma glucose and HbA1c (Figure 7). ${ }^{88}$ Pitavastatin significantly decreased HbAlc in diabetic patients in the LIVES Study $(\mathrm{n}=308)$ (Figure 8). ${ }^{89}$ Although concomitant antidiabetic therapy was continued in the LIVES Study, pitavastatin at least produced no adverse effects on glycemic control in diabetic patients in real clinical settings.

The mechanisms by which some statins have adverse effects on glycemic control remain uncertain, but one of the possible explanations is related to interference with glucose transporter-4 (GLUT4). In 3T3-L1 adipocytes, atorvastatin significantly prevented translocation of GLUT 4 into the plasma membrane, as compared to pravastatin..$^{90}$ Another study examined the effects of statins on glucose uptake using 3T3-L1 cells. Treatment with atorvastatin attenuated glucose transporter-4 (SLC2A4) and $\mathrm{C} / \mathrm{EBP} \alpha$ expressions in differentiated 3T3-L1 adipocytes. Also atorvastatin 1-10 ng/mL significantly decreased glucose uptake in differentiated 3T3-L1 cells, but pitavastatin $10^{2} \mathrm{ng} / \mathrm{mL}$ did not produce any influence. ${ }^{91}$ These differences across several kinds of statins are of great interest and should be confirmed by further studies.

\section{Drug-drug interaction}

Patients treated with statins usually take a number of drugs, and therefore the possibility of drug-drug interactions is an issue to be considered when they are prescribed. Atorvastatin and simvastatin are known to be metabolized by CYP3A4, but pitavastatin is hardly metabolized through this system at all (only slightly metabolized by CYP2C9). ${ }^{4,92}$ For example, diabetic patients often have nail ringworm and take antifungal agents such as itraconazole. Combined administration of itraconazole with CYP3A4-metabolized statin may result in an increased concentration of statin due to strong inhibition of CYP3A4 by itraconazole.

One example is related to grapefruit juice (GFJ), which is known to inhibit CYP3A4. When atorvastatin was taken with $\mathrm{GFJ}$, the mean $\mathrm{AUC}_{0-24}$ of atorvastatin acid significantly increased by $83 \%$, compared to taking atorvastatin with water. By contrast, $\mathrm{AUC}_{0-24}$ of pitavastatin remained similar irrespective of concomitant GFJ or water, ${ }^{93}$ which would be a
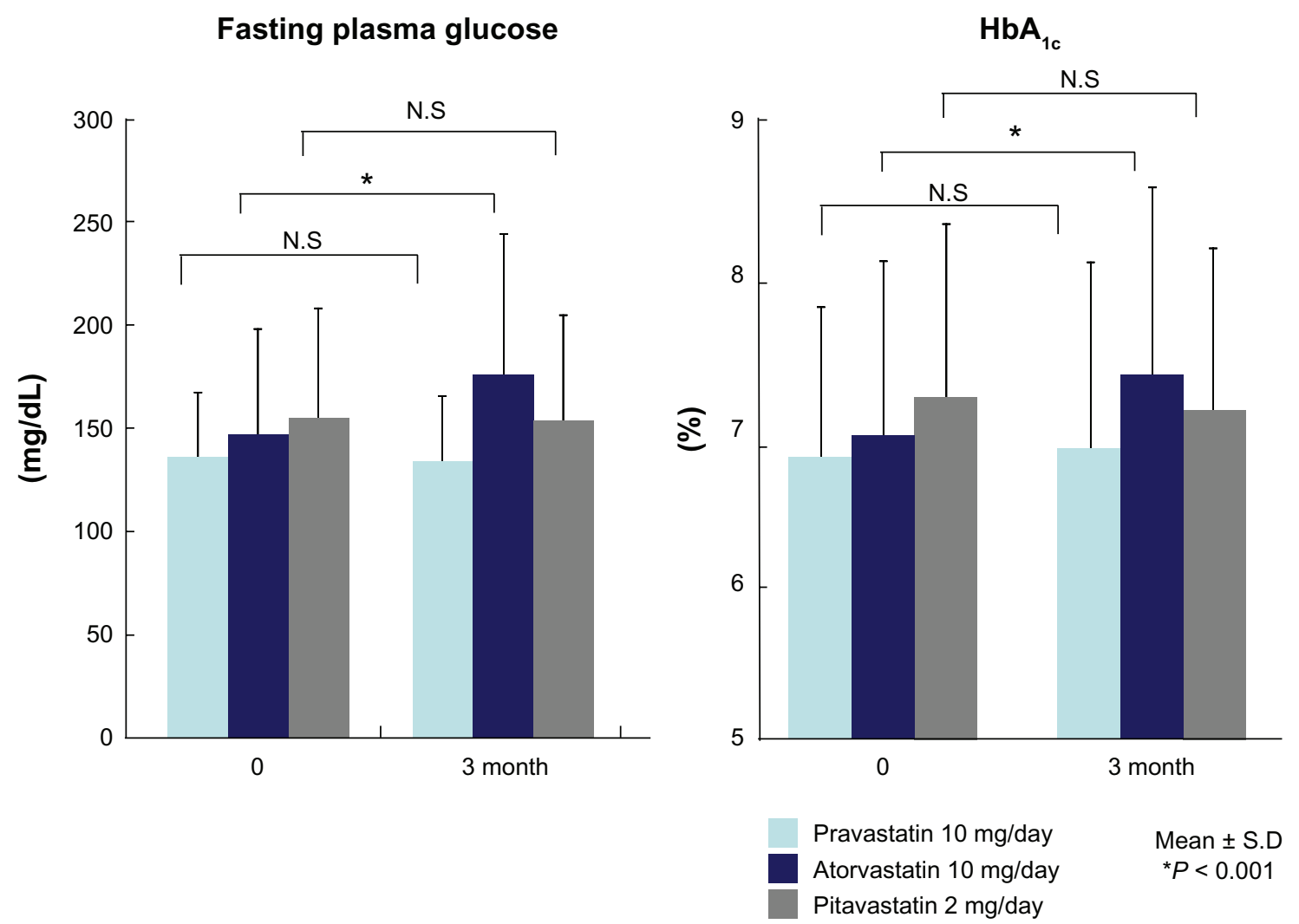

Figure 7 Changes in fasting plasma glucose and HbAlc before and after administration of pravastatin $10 \mathrm{mg} /$ day $(n=70)$, atorvastatin $(n=74)$, and pitavastatin ( $=76)$ in patients with type 2 diabetes mellitus.

Adapted from Yamakawa et al. ${ }^{88}$ 


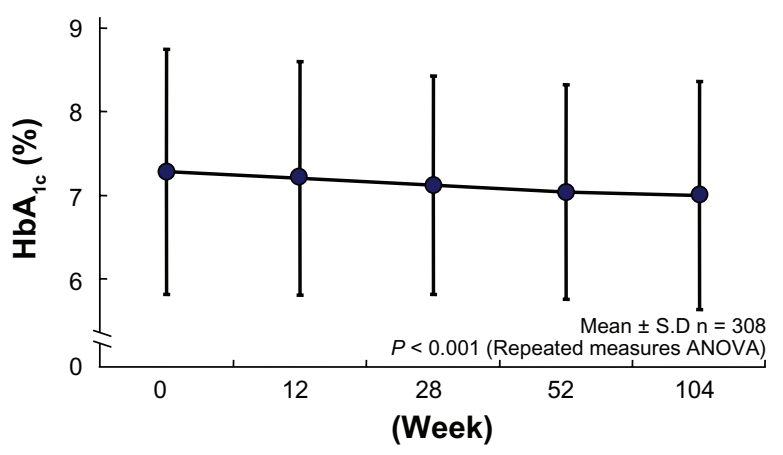

Figure 8 Changes in $\mathrm{HbAlc}$ before and after administration of pitavastatin $\mathrm{I}-4 \mathrm{mg} /$ day in the LIVES study in patients with diabetes mellitus. Adapted from Teramoto et al. ${ }^{89}$

clinical advantage for pitavastatin. Warfarin is another drug that is of concern. CYP2C9 is the primary enzyme in S-warfarin metabolism. Assessing the effects of pitavastatin $4 \mathrm{mg} /$ day on steady-state warfarin in healthy volunteers $(n=24)$, the ratios of the least squares mean of prothrombin time (PT) and international normalized ratio (INR) between the monotherapy of warfarin and the concomitant treatment of warfarin and pitavastatin were 0.989 and 0.993 , respectively, and the $90 \%$ confidence intervals (CIs) were 0.955 to 1.023 for PT and 0.956 to 1.029 for INR. ${ }^{94}$ In this study, no drug-drug interaction between pitavastatin and warfarin was demonstrated.

\section{Adverse event rate}

Statin treatment usually requires long-term administration, and therefore the safety profile is one of the most important factors when considering which kind of statins should be prescribed. In the LIVES Study, approximately 20,000 Japanese patients with hypercholesterolemia or familial hypercholesterolemia were treated for 2 years in order to analyze drug safety and effectiveness. The incidence of adverse drug reactions was $6.1 \%(1,206 / 19,921$ patients) after 3 months of pitavastatin treatment, ${ }^{19} 8.8 \%(1,753 / 19,925$ patients $)$ after 1 year of treatment, ${ }^{95}$ and $10.4 \%(2,069 / 19,925$ patients $)$ after 2 years of treatment. ${ }^{96}$ For other types of statin treatment used in Japan, the incidence of adverse drug reactions was $12.0 \%$ (576/4,805 patients) at 3 months of atorvastatin treatment, ${ }^{97}$ and $11.1 \%(978 / 8,795$ patients $)$ at 3 months of rosuvastatin treatment, ${ }^{98}$ both of which were about twice that of pitavastatin. Looking at laboratory data abnormalities during a 3 month post-marketing survey of each statin, the incidence of CK elevation was 1.41\% (pitavastatin), 2.19\% (atorvastatin), and $2.29 \%$ (rosuvastatin); the incidence of AST elevation was $0.71 \%$ (pitavastatin), $1.14 \%$ (atorvastatin), and $0.53 \%$ (rosuvastatin); the incidence of ALT elevation was $0.90 \%$ (pitavastatin), $1.83 \%$ (atorvastatin), and $0.69 \%$ (rosuvastatin); and the incidence of myalgia was $0.66 \%$ (pitavastatin), $0.50 \%$ (atorvastatin), and $1.43 \%$ (rosuvastatin). In another report from the Japanese Society of Hospital Pharmacists, the incidence of suspicious myopathy was $0.38 \%$ (4/1040) for simvastatin, $0.53 \%$ (17/3229) for pravastatin, $0.50 \%(22 / 4440)$ for atorvastatin, $0.58 \%(2 / 347)$ for fluvastatin, $0.36 \%(3 / 838)$ for pitavastatin, and $1.01 \%$ (9/891) for rosuvastatin. ${ }^{99}$

One of the possible explanations why pitavastatin is associated with a lower incidence of adverse reactions than other potent statins is that pitavastatin can reduce LDL cholesterol effectively and safely without blocking the mevalonate pathway excessively and in turn inducing LDL receptors. When HepG2 cells were treated with a 200-fold excess of the $\mathrm{IC}_{50}$ concentration of three $\mathrm{HMG}-\mathrm{CoA}$ reductase inhibitors (pitavastatin, atorvastatin, and simvastatin), pitavastatin was able to induce LDL receptor mRNA most effectively. ${ }^{7}$ This suggests that pitavastatin could have the additional capability to enhance LDL receptor gene expression, unrelated to HMG-CoA reductase inhibition. Interestingly, a crossover study comparing pitavastatin $4 \mathrm{mg}$ /day with atorvastatin $20 \mathrm{mg} /$ day showed that plasma levels of CoQ10 were reduced by atorvastatin $(-26.1 \%, P=0.0007)$ but not by pitavastatin $(-7.7 \%, P=0.39) .{ }^{100}$

The relationship between statin-related adverse effects and the hepatic drug transporter $S L C O 1 B 1$ genetic variants has been reported. In the SEARCH Study, common variants in $S L C O 1 B 1$ were associated with an increased risk of statin-induced myopathy, and the odds ratio for myopathy was 4.5 per copy of the rs4149056 C allele and 16.9 in CC as compared with TT homozygotes. ${ }^{101}$ Also in the STRENGTH Study, $S L C O 1 B 1 * 5$ genotype and female sex were associated with mild statin-induced adverse effects. ${ }^{102}$ The influence of this genetic variant on pitavastatin-related myopathy should be investigated in future studies.

\section{Ongoing pitavastatin trials}

Additional trials to test the clinical efficacy of pitavastatin in various settings are now underway, and are expected to provide further data.

\section{$\operatorname{REAL-CAD}(n=12,600)$}

REAL-CAD (Randomized Evaluation of Aggressive or Moderate Lipid Lowering Therapy with Pitavastatin in Coronary Artery Disease, NCT 01042730, UMIN 000002680) is a trial to evaluate the prevention of cardiovascular disease by standard cholesterol lowering (pitavastatin $1 \mathrm{mg} /$ day) or aggressive cholesterol lowering (pitavastatin $4 \mathrm{mg} /$ day) in patients with 
stable coronary artery disease. Several large-scale trials such as TNT, A-to-Z, IDEAL and PROVE-IT elucidated the efficacy of aggressive cholesterol lowering for secondary cardiovascular event reduction, and a meta-analysis showed that intensive lipid lowering with high-dose statin therapy showed a significant $(16 \%)$ reduction of odds ratio in the risk of coronary death or myocardial infarction. ${ }^{103}$ Although target LDL cholesterol for patients with coronary artery disease is below $100 \mathrm{mg} / \mathrm{dL}$ in the guidelines of the Japan Atherosclerosis Society, REAL-CAD will provide important information about whether more aggressive cholesterol lowering therapy is beneficial, especially in diabetic subjects.

\section{PEARL study $(\mathrm{n}=577)$}

PEARL Study (Pitavastatin Heart Failure Study, UMIN C000000428) is a comparative and randomized trial to evaluate the effects of pitavastatin $2 \mathrm{mg}$ /day on cardiac death and hospitalization for worsening heart failure in patients with mild-to-moderate heart failure. ${ }^{104}$ Although early studies suggested that statins improve cardiac function, CORONA and GISSI-HF failed to demonstrate the benefit of rosuvastatin therapy in primary endpoints in patients with heart failure, ${ }^{105,106}$ and the effects of statins on cardiac function have remained controversial.

In a small study $(\mathrm{n}=23)$, administration of pitavastatin 1-2 mg/day for 7.5 months significantly increased left ventricular ejection fraction (LVEF) from 42 to $48 \%$, and significantly decreased the plasma brain natriuretic peptide (BNP) level from 94 to $70 \mathrm{pg} / \mathrm{mL} .{ }^{107}$ It has also been reported that there was an inverse correlation between atorvastatininduced changes in CoQ10 and BNP, ${ }^{108}$ that CoQ10 level was an independent predictor of mortality in chronic heart failure, ${ }^{109}$ and that the CoQ10 level in myocardial tissue was lower in patients of NYHA class IV than in patients of NYHA class I. ${ }^{110}$ Considering that pitavastatin does not reduce CoQ10 and is effective in improving vascular function, the results of PEARL Study may be expected to provide new evidence for heart failure treatment with statins.

\section{J-PREDICT $(\mathrm{n}=\mathrm{I}, 240)$}

J-PREDICT (Japan Prevention Trial of Diabetes by Pitavastatin in Patients With Impaired Glucose Tolerance, NCT 00301392, UMIN C000000394) is a comparative and randomized trial to evaluate the prevention of new-onset diabetes using pitavastatin 1-4 mg/day in patients with impaired glucose tolerance (IGT). This will provide a new possibility for the use of statins to control glucose metabolism and the development of diabetes.

\section{DIALYSIS $(n=1,550)$}

DIALYSIS (Differential Intervention Trial by Standard Therapy Versus Pitavastatin in Patients With Chronic Hemodialysis, NCT 00846118) is a trial to evaluate the effects of pitavastatin $1-4 \mathrm{mg} /$ day on all-cause mortality and the incidence of myocardial infarction in hemodialysis patients. In Japan, the primary reason for dialysis is diabetic nephropathy, but few trials have evaluated the effects of statins on cardiovascular diseases in dialyzed patients. In a 4D trial by atorvastatin ${ }^{111}$ and AURORA by rosuvastatin, ${ }^{112}$ statin therapy did not show any benefit on the primary endpoint such as cardiovascular disease or all-cause mortality. However, in 4D subanalysis, atorvastatin treatment led to a $46 \%$ risk reduction of all composite cardiovascular endpoints, a $52 \%$ decrease of sudden cardiac death, and a $28 \%$ decrease of all-cause mortality among patients in the highest LDL cholesterol quartile (greater than $145 \mathrm{mg} / \mathrm{dL}$ ). ${ }^{113}$ DIALYSIS is expected to provide the first evidence of statin use in Asian patients with hemodialysis.

\section{TOHO-LIP $(\mathrm{n}=600)$}

TOHO-LIP (TOHO lipid intervention trial using Pitavastatin, UMIN 000001404) is a trial to evaluate the prevention of various macrovascular diseases by pitavastatin or atorvastatin in subjects at high risk of cardiovascular disease. Although pitavastatin $2 \mathrm{mg} /$ day and atorvastatin $10 \mathrm{mg} /$ day are generally considered to show similar LDL cholesterol lowering effects, it has also been reported that pitavastatin $2 \mathrm{mg} /$ day is superior to atorvastatin $10 \mathrm{mg} /$ day in LDL cholesterol lowering in metabolic syndrome patients. ${ }^{22}$ Therefore, a comparative study using pitavastatin and atorvastatin in specific patient populations is of interest.

\section{Extended-JAPAN-ACS $(n=252)$}

The Extended-JAPAN-ACS (Extended Japan Assessment of Pitavastatin and Atorvastatin in Acute Coronary Syndrome, NCT 01223586, UMIN 000003166) trial was carried out to verify the relationship between coronary plaque regression and cardiovascular events in long-term follow-up in ACS patients enrolled in JAPAN-ACS. There are few reports which elucidate the relationship between coronary artery plaque regression and cardiovascular event reduction, ${ }^{114}$ and therefore the Extended-JAPAN-ACS trial could add further evidence useful for secondary prevention in the Japanese population.

\section{Prospects and conclusion}

Based on these findings, pitavastatin has a number of favorable characteristics that are beneficial in patients with 
diabetes mellitus, which are derived from its efficacy and safety; potency in LDL cholesterol reduction; sustained HDL cholesterol raising effect; beneficial vascular effects; anti-inflammatory and antioxidant effects; improvement of insulin resistance; minimal influence on glucose metabolism; minimal drug-drug interaction; and low incidence of adverse effects. The maximum dose of pitavastatin allowed in Japan is $4 \mathrm{mg} /$ day, and it reduces LDL cholesterol by $47 \%$. Judging from the unique characteristics of pitavastatin as reviewed in this article, this Japanese-oriented statin could provide alternative treatment choice especially in patients with glucose intolerance or diabetes mellitus.

Considering very recent publications about experimental studies using nanoparticle (NP)-mediated delivery of pitavastatin in limb ischemia models ${ }^{115,116}$ and pulmonary artery hypertension models, ${ }^{117}$ information is likely to be obtained from current clinical trials that will expand the possible applications of pitavastatin.

\section{Disclosure}

The authors report no conflicts of interest in this work.

\section{References}

1. Cholesterol Treatment Trialists' (CTT) Collaboration, Baigent C, Blackwell L, Emberson J, et al. Efficacy and safety of more intensive lowering of LDL cholesterol: a meta-analysis of data from 170,000 participants in 26 randomised trials. Lancet. 2010;376(9753):1670-1681.

2. Endo A. The discovery and development of HMG-CoA reductase inhibitors. J Lipid Res. 1992;33(11):1569-1582.

3. Kimata H, Fujino H, Koide T, Yamada Y, Tsunenari Y, Yanagawa Y. Studies on the metabolic fate of NK-104, a new Inhibitor of HMG-CoA reductase (1): Absorption, distribution, metabolism and excretion in rats. Drug Metab Pharmacokinet. 1998;13(5):484-499.

4. Saito Y. Critical appraisal of the role of pitavastatin in treating dyslipidemias and achieving lipid goals. Vasc Health Risk Manag. 2009;5: 921-936.

5. Catapano AL. Pitavastatin - pharmacological profile from early phase studies. Atheroscler Suppl. 2010;11(3):3-7.

6. Yamazaki H, Fujino H, Kanazawa M, et al. Pharmacological and pharmacokinetic features and clinical effects of pitavastatin (Livalo Tablet $\left.{ }^{\mathbb{}}\right)$. Nippon Yakurigaku Zasshi. 2004;123(5):349-362. Japanese.

7. Morikawa S, Umetani M, Nakagawa S, et al. Relative induction of mRNA for HMG CoA reductase and LDL receptor by five different HMG-CoA reductase inhibitors in cultured human cells. $J$ Atheroscler Thromb. 2000;7(3):138-144.

8. Aoki T, Nishimura H, Nakagawa S, et al. Pharmacological profile of a novel synthetic inhibitor of 3-hydroxy-3-methylglutaryl-coenzyme A reductase. Arzneimittelforschung. 1997;47(8):904-909.

9. Gaede P, Vedel P, Larsen N, Jensen GV, Parving HH, Pedersen O. Multifactorial intervention and cardiovascular disease in patients with type 2 diabetes. $N$ Engl J Med. 2003;348(5):383-393.

10. Gaede P, Lund-Andersen H, Parving HH, Pedersen O. Effect of a multifactorial intervention on mortality in type 2 diabetes. $N$ Engl $J$ Med. 2008;358(6):580-591.

11. Action to Control Cardiovascular Risk in Diabetes Study Group, Gerstein HC, Miller ME, Byington RP, et al. Effects of intensive glucose lowering in type 2 diabetes. $N$ Engl J Med. 2008;358(24): $2545-2559$.
12. ADVANCE Collaborative Group, Patel A, MacMahon S, Chalmers J, et al. Intensive blood glucose control and vascular outcomes in patients with type 2 diabetes. N Engl J Med. 2008;358(24):2560-2572.

13. Turner RC, Millns H, Neil HA, et al. Risk factors for coronary artery disease in non-insulin dependent diabetes mellitus: United Kingdom Prospective Diabetes Study (UKPDS: 23). BMJ. 1998; 316(7134):823-828.

14. Sone H, Yamada N. Japan Diabetes Complications Study (JDCS). Nippon Rinsho. 2010;68(5):865-871. Japanese.

15. Cholesterol Treatment Trialists' (CTT) Collaborators, Kearney PM, Blackwell L, Collins R, et al. Efficacy of cholesterol-lowering therapy in 18,686 people with diabetes in 14 randomised trials of statins: a meta-analysis. Lancet. 2008;371(9607):117-125.

16. Teramoto T, Sasaki J, Ueshima H, et al. Executive summary of Japan Atherosclerosis Society (JAS) guideline for diagnosis and prevention of atherosclerotic cardiovascular diseases for Japanese. $J$ Atheroscler Thromb. 2007;14(2):45-50.

17. Brunzell JD, Davidson M, Furberg CD, et al. Lipoprotein management in patients with cardiometabolic risk: consensus conference report from the American Diabetes Association and the American College of Cardiology Foundation. J Am Coll Cardiol. 2008;51(15): $1512-1524$

18. Saito Y, Teramoto T, Yamada N, et al. Clinical Efficacy of NK104 (Pitavastatin), a New Synthetic HMG-CoA Reductase inhibitor, in the Dose Finding, Double Blind, Three-group Comparative Study. J Clin Ther Med. 2001;17(6):829-855. Japanese (English abstract).

19. Kurihara Y, Douzono T, Kawakita K, Fujita S, Nachi S, Nagasaka Y. A Large-scale, Prospective Post-marketing Surveillance of Pitavastatin (LIVALO ${ }^{\circledR}$ Tablet)-Drug Use Investigation. Jpn Pharmacol Ther. 2007;35(1):9-40. Japanese (English abstract).

20. Hiro T, Kimura T, Morimoto T, et al; JAPAN-ACS Investigators. Diabetes mellitus is a major negative determinant of coronary plaque regression during statin therapy in patients with acute coronary syndrome - serial intravascular ultrasound observations from the Japan Assessment of Pitavastatin and Atorvastatin in Acute Coronary Syndrome Trial (the JAPAN-ACS Trial). Circ J. 2010;74(6): $1165-1174$.

21. Nomura S, Shouzu A, Omoto S, et al. Correlation between adiponectin and reduction of cell adhesion molecules after pitavastatin treatment in hyperlipidemic patients with type 2 diabetes mellitus. Thromb Res. 2008;122(1):39-45.

22. Yokote $\mathrm{K}$, Bujo H, Hanaoka H, et al. Multicenter collaborative randomized parallel group comparative study of pitavastatin and atorvastatin in Japanese hypercholesterolemic patients: collaborative study on hypercholesterolemia drug intervention and their benefits for atherosclerosis prevention (CHIBA study). Atherosclerosis. 2008;201(2):345-352.

23. Ose L, Budinski D, Hounslow N, Arneson V. Comparison of pitavastatin with simvastatin in primary hypercholesterolaemia or combined dyslipidaemia. Curr Med Res Opin. 2009;25(11):2755-2764.

24. Budinski D, ArnesonV, Hounslow N, Gratsiansky N. Pitavastatin compared with atorvastatin in primary hypercholesterolemia or combined dyslipidemia. Clin Lipidol. 2009;4(3):291-302.

25. Rosenson RS. Management of non-high-density lipoprotein abnormalities. Atherosclerosis. 2009;207(2):328-335.

26. Hotta K, Funahashi T, Arita Y, et al. Plasma concentrations of a novel, adipose-specific protein, adiponectin, in type 2 diabetic patients. Arterioscler Thromb Vasc Biol. 2000;20(6):1595-1599.

27. Oikawa S, Kita T, Mabuchi H, et al; J-LIT Study Group. Risk of coronary events in Japanese patients with both hypercholesterolemia and type 2 diabetes mellitus on low-dose simvastatin therapy: implication from Japan Lipid Intervention Trial (J-LIT). Atherosclerosis. 2007;191(2): 440-446.

28. Teramoto T, Saito Y, Yamada N, et al. Clinical Safety and Efficacy of NK-104 (Pitavastatin), a New Synthetic HMG-CoA Reductase Inhibitor, in the Long-term Treatment of Hyperlipidemia. Results of a Multicenter Long-term Study. J Clin Ther Med. 2001;17(6):885-913. Japanese (English abstract). 
29. Teramoto T, Shimano H, Yokote K, Urashima M. Effects of pitavastatin (LIVALO Tablet) on high density lipoprotein cholesterol (HDL-C) in hypercholesterolemia. J Atheroscler Thromb. 2009;16(5):654-661.

30. Sasaki J, Ikeda Y, Kuribayashi T, et al. A 52-week, randomized, open-label, parallel-group comparison of the tolerability and effects of pitavastatin and atorvastatin on high-density lipoprotein cholesterol levels and glucose metabolism in Japanese patients with elevated levels of low-density lipoprotein cholesterol and glucose intolerance. Clin Ther. 2008;30(6):1089-1101.

31. Ose L, Budinski D, Hounslow N, Arneson V. Long-term treatment with pitavastatin is effective and well tolerated by patients with primary hypercholesterolemia or combined dyslipidemia. Atherosclerosis. 2010;210(1):202-208.

32. Martin G, Duez H, Blanquart C, et al. Statin-induced inhibition of the Rho-signaling pathway activates PPARalpha and induces HDL apoA-I. J Clin Invest. 2001;107(11):1423-1432.

33. Zanotti I, Favari E, Sposito AC, Rothblat GH, Bernini F. Pitavastatin increases ABCA1-mediated lipid efflux from Fu5AH rat hepatoma cells. Biochem Biophys Res Commun. 2004;321(3):670-674.

34. Kawano M, Nagasaka S, Yagyu H, Ishibashi S. Pitavastatin decreases plasma prebeta1-HDL concentration and might promote its disappearance rate in hypercholesterolemic patients. J Atheroscler Thromb. 2008; 15(1):41-46.

35. Maejima T, Yamazaki H, Aoki T, et al. Effect of pitavastatin on apolipoprotein A-I production in HepG2 cell. Biochem Biophys Res Commun. 2004;324(2):835-839.

36. Shimano H, Arai H, Harada-Shiba M, et al. Proposed guidelines for hypertriglyceridemia in Japan with non-HDL cholesterol as the second target. J Atheroscler Thromb. 2008;15(3):116-121.

37. Lu W, Resnick HE, Jablonski KA, et al. Non-HDL cholesterol as a predictor of cardiovascular disease in type 2 diabetes: the strong heart study. Diabetes Care. 2003;26(1):16-23.

38. Watanabe N, Taniguchi T, Taketoh H, et al. Elevated remnant-like lipoprotein particles in impaired glucose tolerance and type 2 diabetic patients. Diabetes Care. 1999;22(1):152-156.

39. Hirano T, Ito Y, Koba S, et al. Clinical significance of small dense lowdensity lipoprotein cholesterol levels determined by the simple precipitation method. Arterioscler Thromb Vasc Biol. 2004;24(3):558-563.

40. Yamada N, Kawazu S, Utsugi T, et al. Efficacy of pitavastatin for lipid metabolism in non-insulin-dependent diabetes mellitus. $J$ Clin Ther Med. 2001;17(6):945-956. Japanese (English abstract).

41. Tokuno A, Hirano T, Hayashi T, et al. The effects of statin and fibrate on lowering small dense LDL- cholesterol in hyperlipidemic patients with type 2 diabetes. J Atheroscler Thromb. 2007;14(3):128-132.

42. Versari D, Daghini E, Virdis A, Ghiadoni L, Taddei S. Endothelial dysfunction as a target for prevention of cardiovascular disease. Diabetes Care. 2009;32(Suppl 2):S314-S321.

43. Hadi HA, Suwaidi JA. Endothelial dysfunction in diabetes mellitus. Vasc Health Risk Manag. 2007;3(6):853-876.

44. Imanishi $\mathrm{T}$, Ikejima $\mathrm{H}$, Tsujioka $\mathrm{H}$, et al. Combined effects of an 3-hydroxy-3-methylglutaryl coenzyme A reductase inhibitor and angiotensin II receptor antagonist on nitric oxide bioavailability and atherosclerotic change in myocardial infarction-prone Watanabe heritable hyperlipidemic rabbits. Hypertens Res. 2008;31(6): 1199-1208.

45. Ota H, Eto M, Kano MR, et al. Induction of endothelial nitric oxide synthase, SIRT1, and catalase by statins inhibits endothelial senescence through the Akt pathway. Arterioscler Thromb Vasc Biol. 2010; 30(11):2205-2211.

46. Sakabe K, Fukuda N, Fukuda Y, et al. Comparisons of short- and intermediate-term effects of pitavastatin versus atorvastatin on lipid profiles, fibrinolytic parameter, and endothelial function. Int J Cardiol. 2008;125(1):136-138.

47. Miyashita Y, Endo K, Saiki A, et al. Effects of pitavastatin, a 3-hydroxy3-methylglutaryl coenzyme a reductase inhibitor, on cardio-ankle vascular index in type 2 diabetic patients. J Atheroscler Thromb. 2009;16(5): $539-545$.
48. Nasu K, Tsuchikane E, Katoh O, et al. Plaque characterisation by virtual histology intravascular ultrasound analysis in patients with type 2 diabetes. Heart. 2008;94(4):429-433.

49. Nicholls SJ, Tuzcu EM, Kalidindi S, et al. Effect of diabetes on progression of coronary atherosclerosis and arterial remodeling: a pooled analysis of 5 intravascular ultrasound trials. $\mathrm{JAm} \mathrm{Coll} \mathrm{Cardiol}$. 2008;52(4):255-262.

50. Hiro T, Kimura T, Morimoto T, et al; JAPAN-ACS Investigators. Effect of intensive statin therapy on regression of coronary atherosclerosis in patients with acute coronary syndrome: a multicenter randomized trial evaluated by volumetric intravascular ultrasound using pitavastatin versus atorvastatin (JAPAN-ACS [Japan assessment of pitavastatin and atorvastatin in acute coronary syndrome] study). $\mathrm{J} \mathrm{Am} \mathrm{Coll} \mathrm{Cardiol.}$ 2009;54(4):293-302.

51. Arai H, Hiro T, Kimura T, et al; JAPAN-ACS Investigators. More intensive lipid lowering is associated with regression of coronary atherosclerosis in diabetic patients with acute coronary syndrome - sub-analysis of JAPAN-ACS study. J Atheroscler Thromb. 2010;17(10):1096-1107.

52. Toi T, Taguchi I, Yoneda S, et al. Early effect of lipid-lowering therapy with pitavastatin on regression of coronary atherosclerotic plaque. Comparison with atorvastatin. Circ J. 2009;73(8):1466-1472.

53. Matsuoka H, Kawakami H, Nakamura M, Komatsu J. Evaluation of Thrombi and Plaque in Saphenous Vein Graft by Angioscopy. J Jpn Coll Angiol. 2007;47:77-83. Japanese (English abstract).

54. Kodama K, Komatsu S, Ueda Y, et al. Stabilization and regression of coronary plaques treated with pitavastatin proven by angioscopy and intravascular ultrasound - the TOGETHAR trial. Circ J. 2010;74(9): $1922-1928$.

55. Nakamura T, Obata JE, Kitta Y, et al. Rapid stabilization of vulnerable carotid plaque within 1 month of pitavastatin treatment in patients with acute coronary syndrome. J Cardiovasc Pharmacol. 2008;51(4): $365-371$.

56. Honda O, Sugiyama S, Kugiyama K, et al. Echolucent carotid plaques predict future coronary events in patients with coronary artery disease. J Am Coll Cardiol. 2004;43(7):1177-1184.

57. Chronic Kidney Disease Prognosis Consortium, Matsushita K, van der Velde M, Astor BC, et al. Association of estimated glomerular filtration rate and albuminuria with all-cause and cardiovascular mortality in general population cohorts: a collaborative meta-analysis. Lancet. 2010;375(9731):2073-2081.

58. Kimura K, Shimano H, Yokote K, Urashima M, Teramoto T. Effects of pitavastatin (LIVALO tablet) on the estimated glomerular filtration rate (eGFR) in hypercholesterolemic patients with chronic kidney disease. Sub-analysis of the LIVALO Effectiveness and Safety (LIVES) Study. J Atheroscler Thromb. 2010;17(6):601-609.

59. Athyros VG, Kakafika AI, Papageorgiou AA, et al. Statin-Induced Increase in HDL-C and Renal Function in Coronary Heart Disease Patients. Open Cardiovasc Med J. 2007;1:8-14.

60. Nakamura T, Sugaya T, Kawagoe Y, Ueda Y, Osada S, Koide H. Effect of pitavastatin on urinary liver-type fatty acid-binding protein levels in patients with early diabetic nephropathy. Diabetes Care. 2005;28(11): 2728-2732.

61. Moorhead JF, Chan MK, El-Nahas M, Varghese Z. Lipid nephrotoxicity in chronic progressive glomerular and tubulo-interstitial disease. Lancet.1982;2(8311):1309-1311.

62. Ruan XZ, Varghese Z, Moorhead JF. An update on the lipid nephrotoxicity hypothesis. Nat Rev Nephrol. 2009;5(12):713-721.

63. Durrington PN, Mackness B, Mackness MI. Paraoxonase and atherosclerosis. Arterioscler Thromb Vasc Biol. 2001;21(4):473-480.

64. Ota K, Suehiro T, Arii K, et al. Effect of pitavastatin on transactivation of human serum paraoxonase 1 gene. Metabolism. 2005;54(2):142-150.

65. Liang XM, Otani H, Zhou Q, et al. Renal protective effects of pitavastatin on spontaneously hypercholesterolaemic Imai Rats. Nephrol Dial Transplant. 2007;22(8):2156-2164.

66. Jin-Song HE, Horikoshi S, Funabiki K, Shirato I, Tomino Y. Effect of NK-104 on proliferation of cells. Hong Kong J Nephrol. 2001;3(2): $67-73$. 
67. Toyohara T, Suzuki T, Morimoto R, et al. SLCO4C1 transporter eliminates uremic toxins and attenuates hypertension and renal inflammation. J Am Soc Nephrol. 2009;20(12):2546-2555.

68. Ridker PM, Cannon CP, Morrow D, et al; Pravastatin or Atorvastatin Evaluation and Infection Therapy-Thrombolysis in Myocardial Infarction 22 (PROVE IT-TIMI 22) Investigators. C-reactive protein levels and outcomes after statin therapy. $N$ Engl J Med. 2005;352(1):20-28.

69. Arima H, Kubo M, Yonemoto K, et al. High-sensitivity C-reactive protein and coronary heart disease in a general population of Japanese: the Hisayama study. Arterioscler Thromb Vasc Biol. 2008;28(7): 1385-1391.

70. Ridker PM, Danielson E, Fonseca FA, et al; JUPITER Study Group. Rosuvastatin to prevent vascular events in men and women with elevated C-reactive protein. $N$ Engl J Med. 2008;359(21):2195-2207.

71. Doi Y, Kiyohara Y, Kubo M, et al. Elevated C-reactive protein is a predictor of the development of diabetes in a general Japanese population: the Hisayama Study. Diabetes Care. 2005;28(10):2497-2500.

72. Freeman DJ, Norrie J, Caslake MJ, et al; West of Scotland Coronary Prevention Study. C-reactive protein is an independent predictor of risk for the development of diabetes in the West of Scotland Coronary Prevention Study. Diabetes. 2002;51(5):1596-1600.

73. Koshiyama H, Taniguchi A, Tanaka K, et al; Kansai Investigation of Statin for Hyperlipidemic Intervention in Metabolism and Endocrinology Investigators. Effects of pitavastatin on lipid profiles and highsensitivity CRP in Japanese subjects with hypercholesterolemia: Kansai Investigation of Statin for Hyperlipidemic Intervention in Metabolism and Endocrinology (KISHIMEN) investigators. J Atheroscler Thromb. 2008;15(6):345-350.

74. Ehara S, Ueda M, Naruko T, et al. Elevated levels of oxidized low density lipoprotein show a positive relationship with the severity of acute coronary syndromes. Circulation. 2001;103(15):1955-1960.

75. Holvoet P, Collen D, Van de Werf F. Malondialdehyde-modified LDL as a marker of acute coronary syndromes. JAMA. 1999;281(18): 1718-1721

76. Tsimikas S, Bergmark C, Beyer RW, et al. Temporal increases in plasma markers of oxidized low-density lipoprotein strongly reflect the presence of acute coronary syndromes. J Am Coll Cardiol. 2003;41(3): 360-370.

77. Sakuraba H, Mizukami H, Yagihashi N, Wada R, Hanyu C, Yagihashi S. Reduced beta-cell mass and expression of oxidative stress-related DNA damage in the islet of Japanese Type II diabetic patients. Diabetologia. 2002;45(1):85-96.

78. Matsumoto T, Fujita M, Sawamura T, et al. Pitavastatin reduces lectinlike oxidized low-density lipoprotein receptor-1 ligands in hypercholesterolemic humans. Lipids. 2010;45(4):329-335.

79. Freeman DJ, Norrie J, Sattar N, et al. Pravastatin and the development of diabetes mellitus: evidence for a protective treatment effect in the West of Scotland Coronary Prevention Study. Circulation. 2001;103(3): 357-362.

80. Iwai M. Effects of HMG-CoA Reductase Inhibitor, Pitavastatin on impaired glucose tolerance and vascular injury in KKA ${ }^{y}$ mice. Ther Res. 2003;24(7):1329-1337. Japanese.

81. Ishihara Y, Ohmori K, Mizukawa M, Hasan AU, Noma T, Kohno M. Beneficial direct adipotropic actions of pitavastatin in vitro and their manifestations in obese mice. Atherosclerosis. 2010;212(1):131-138.

82. Katayama T. Usefulness of pitavastatin on lipid profile and glucose metabolism in hypercholesterolemia with diabetes mellitus. Prog Med. 2005;25:3110-3115. Japanese.

83. Drew BG, Duffy SJ, Formosa MF, et al. High-density lipoprotein modulates glucose metabolism in patients with type 2 diabetes mellitus. Circulation. 2009;119(15):2103-2111.

84. Padwal R, Majumdar SR, Johnson JA, Varney J, McAlister FA. A systematic review of drug therapy to delay or prevent type 2 diabetes. Diabetes Care. 2005;28(3):736-744.

85. Rajpathak SN, Kumbhani DJ, Crandall J, Barzilai N, Alderman M, Ridker PM. Statin therapy and risk of developing type 2 diabetes: a meta-analysis. Diabetes Care. 2009;32(10):1924-1929.
86. Sattar N, Preiss D, Murray HM, et al. Statins and risk of incident diabetes: a collaborative meta-analysis of randomised statin trials. Lancet. 2010;375(9716):735-742.

87. Yokote K, Saito Y; CHIBA study investigators. Influence of statins on glucose tolerance in patients with type 2 diabetes mellitus: subanalysis of the collaborative study on hypercholesterolemia drug intervention and their benefits for atherosclerosis prevention (CHIBA study). J Atheroscler Thromb. 2009;16(3):297-298.

88. Yamakawa T, Takano T, Tanaka S, Kadonosono K, Terauchi Y. Influence of pitavastatin on glucose tolerance in patients with type 2 diabetes mellitus. J Atheroscler Thromb. 2008;15(5):269-275.

89. Teramoto T, Shimano H, Yokote K, Urashima M. New evidence on pitavastatin: efficacy and safety in clinical studies. Expert Opin Pharmacother. 2010;11(5):817-828.

90. Takaguri A, Satoh K, Itagaki M, Tokumitsu Y, Ichihara K. Effects of atorvastatin and pravastatin on signal transduction related to glucose uptake in 3T3L1 adipocytes. J Pharmacol Sci. 2008;107(1): 80-89.

91. Nakata M, Nagasaka S, Kusaka I, Matsuoka H, Ishibashi S, Yada T. Effects of statins on the adipocyte maturation and expression of glucose transporter 4 (SLC2A4): implications in glycaemic control. Diabetologia. 2006;49(8):1881-1892.

92. Mukhtar RY, Reid J, Reckless JP. Pitavastatin. Int J Clin Pract. 2005; 59(2):239-252.

93. Ando H, Tsuruoka S, Yanagihara H, et al. Effects of grapefruit juice on the pharmacokinetics of pitavastatin and atorvastatin. $\mathrm{Br} \mathrm{J}$ Clin Pharmacol. 2005;60(5):494-497.

94. Inagaki $Y$, Hunt $T$, Arana B, Gosho M, Morgan R. Drug-Drug Interaction Study to Assess the Effects of Multiple-Dose Pitavastatin on Steady-State Warfarin in Healthy Adult Volunteers. J Clin Pharmacol. 2011. [Epub ahead of print].

95. Kurihara Y, Douzono T, Kawakita K, Nachi S, Nagasaka Y. A Large-scale, Long-term, Prospective Post-marketing Surveillance of Pitavastatin (LIVALO ${ }^{\circledR}$ Tablet)-LIVALO Effectiveness and Safety (LIVES) Study Interim (52 weeks) Report. Jpn Pharmacol Ther. 2008;36(1):9-28. Japanese (English abstract).

96. Kurihara Y, Douzono T, Kawakita K, Nagasaka Y. A Large - scale, Long-term, Prospective Post-marketing Surveillance of Pitavastatin (LIVALO ${ }^{\circledR}$ Tablet)-LIVALO Effectiveness and Safety (LIVES) Study. Jpn Pharmacol Ther. 2008;36(8):709-731.

97. Komano N, Masaki M, Kawai H, Kubota Y, Kajiura T. The safety and efficacy in post-marketing surveillance of atorvastatin. Prog Med. 2005;25:131-142. Japanese.

98. Yoshida S. The safety and efficacy in post-marketing surveillance of rosuvastatin. Prog Med. 2007;27:1159-1189. Japanese.

99. Orii T, Ishimoto K, Tsukamoto H, et al. The research of appropriate drug application by using pharmacoepidemiological method (Final report). J Jpn Soc Hosp Pharm. 2010;46(8):993-997. Japanese.

100. Kawashiri MA, Nohara A, Tada H, et al. Comparison of effects of pitavastatin and atorvastatin on plasma coenzyme Q10 in heterozygous familial hypercholesterolemia: results from a crossover study. Clin Pharmacol Ther. 2008;83(5):731-739.

101. SEARCH Collaborative Group, Link E, Parish S, Armitage J, et al. SLCO1B1 variants and statin-induced myopathy-a genomewide study. N Engl J Med. 2008;359(8):789-799.

102. Voora D, Shah SH, Spasojevic I, et al. The SLCO1B1*5 genetic variant is associated with statin-induced side effects. J Am Coll Cardiol. 2009;54(17):1609-1616.

103. Cannon CP, Steinberg BA, Murphy SA, Mega JL, Braunwald E. Meta-analysis of cardiovascular outcomes trials comparing intensive versus moderate statin therapy. J Am Coll Cardiol. 2006;48(3): $438-445$.

104. Mizuma H, Inoue T, Takano H, et al; On behalf of the PEARL Study Investigators. Rationale and design of a study to evaluate effects of pitavastatin on Japanese patients with chronic heart failure The pitavastatin heart failure study (PEARL study). Int J Cardiol. 2010. [Epub ahead of print]. 
105. Kjekshus J, Apetrei E, Barrios V, et al; CORONA Group. Rosuvastatin in older patients with systolic heart failure. $N$ Engl $J$ Med. 2007;357(22):2248-2261.

106. Gissi-HF Investigators, Tavazzi L, Maggioni AP, Marchioli R, et al. Effect of rosuvastatin in patients with chronic heart failure (the GISSI-HF trial): a randomised, double-blind, placebo-controlled trial. Lancet. 2008;372(9645):1231-1239.

107. Aoyagi T, Nakamura F, Tomaru T, Toyo-Oka T. Beneficial effects of pitavastatin, a 3-hydroxy-3-methylglutaryl coenzyme a reductase inhibitor, on cardiac function in ischemic and nonischemic heart failure. Int Heart J. 2008;49(1):49-58.

108. Suzuki T, Nozawa T, Sobajima M, et al. Atorvastatin-induced changes in plasma coenzyme q10 and brain natriuretic peptide in patients with coronary artery disease. Int Heart J. 2008;49(4):423-433.

109. Molyneux SL, Florkowski CM, George PM, et al. Coenzyme Q10: an independent predictor of mortality in chronic heart failure. $J \mathrm{Am}$ Coll Cardiol. 2008;52(18):1435-1441.

110. Folkers K, Vadhanavikit S, Mortensen SA. Biochemical rationale and myocardial tissue data on the effective therapy of cardiomyopathy with coenzyme Q10. Proc Natl Acad Sci U S A. 1985;82(3):901-904.

111. Wanner C, Krane V, März W, et al; German Diabetes and Dialysis Study Investigators. Atorvastatin in patients with type 2 diabetes mellitus undergoing hemodialysis. N Engl J Med. 2005;353(3):238-248.
112. Fellström BC, Jardine AG, Schmieder RE, et al; AURORA Study Group. Rosuvastatin and cardiovascular events in patients undergoing hemodialysis. N Engl J Med. 2009;360(14):1395-1407.

113. The European Renal Association-European Dialysis and Transplant Association 2010 Congress.

114. Von Birgelen C, Hartmann M, Mintz GS, et al. Relationship between cardiovascular risk as predicted by established risk scores versus plaque progression as measured by serial intravascular ultrasound in left main coronary arteries. Circulation. 2004;110(12):1579-1585.

115. Kubo M, Egashira K, Inoue T, et al. Therapeutic neovascularization by nanotechnology-mediated cell-selective delivery of pitavastatin into the vascular endothelium. Arterioscler Thromb Vasc Biol. 2009;29(6):796-801.

116. Oda S, Nagahama R, Nakano K, et al. Nanoparticle-mediated endothelial cell-selective delivery of pitavastatin induces functional collateral arteries (therapeutic arteriogenesis) in a rabbit model of chronic hind limb ischemia. J Vasc Surg. 2010;52(2):412-420.

117. Chen L, Nakano K, Kimura S, et al. Nanoparticle-mediated delivery of pitavastatin into lungs ameliorates the development and induces regression of monocrotaline-induced pulmonary artery hypertension. Hypertension. 2011;57(2):343-350.
Drug Design, Development and Therapy

\section{Publish your work in this journal}

Drug Design, Development and Therapy is an international, peerreviewed open-access journal that spans the spectrum of drug design and development through to clinical applications. Clinical outcomes, patient safety, and programs for the development and effective, safe, and sustained use of medicines are a feature of the journal, which

\section{Dovepress}

has also been accepted for indexing on PubMed Central. The manuscript management system is completely online and includes a very quick and fair peer-review system, which is all easy to use. Visit http://www.dovepress.com/testimonials.php to read real quotes from published authors.

Submit your manuscript here: http://www.dovepress.com/drug-design-development-and-therapy-journal 